Review

\title{
Risk Factors and Preventions of Breast Cancer
}

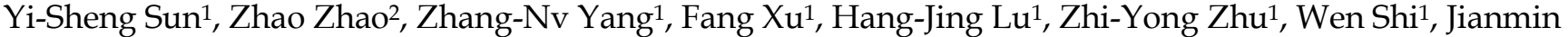 \\ Jiang1, Ping-Ping Yao ${ }^{\boxplus}$, Han-Ping Zhu ${ }^{1 凶}$ \\ 1. Key Lab of Vaccine against Hemorrhagic Fever with Renal Syndrome, Zhejiang Provincial Center for Disease Control and Prevention, Hangzhou, China; \\ 2. Centre of Laboratory Medicine, Zhejiang Provincial People's Hospital. \\ $\triangle$ Corresponding authors: Ping-ping Yao, Key Lab of Vaccine against Hemorrhagic Fever with Renal Syndrome, Zhejiang Provincial Center for Disease Control \\ and Prevention, Hangzhou, China. Phone: 86-571-87115312; Fax: 86-571-87115314; E-mail: ppyao@cdc.zj.cn. Han-Ping Zhu, Key Lab of Vaccine against \\ Hemorrhagic Fever with Renal Syndrome, Zhejiang Provincial Center for Disease Control and Prevention, Hangzhou, China. Phone: 86-571-87115313; Fax: \\ 86-571-87115316; E-mail: hpzhu@cdc.zj.cn.
}

(c) Ivyspring International Publisher. This is an open access article distributed under the terms of the Creative Commons Attribution (CC BY-NC) license (https://creativecommons.org/licenses/by-nc/4.0/). See http://ivyspring.com/terms for full terms and conditions.

Received: 2017.06.26; Accepted: 2017.08.28; Published: 2017.11.01

\begin{abstract}
Breast cancer is the second leading cause of cancer deaths among women. The development of breast cancer is a multi-step process involving multiple cell types, and its prevention remains challenging in the world. Early diagnosis of breast cancer is one of the best approaches to prevent this disease. In some developed countries, the 5-year relative survival rate of breast cancer patients is above $80 \%$ due to early prevention. In the recent decade, great progress has been made in the understanding of breast cancer as well as in the development of preventative methods. The pathogenesis and tumor drug-resistant mechanisms are revealed by discovering breast cancer stem cells, and many genes are found related to breast cancer. Currently, people have more drug options for the chemoprevention of breast cancer, while biological prevention has been recently developed to improve patients' quality of life. In this review, we will summarize key studies of pathogenesis, related genes, risk factors and preventative methods on breast cancer over the past years. These findings represent a small step in the long fight against breast cancer.
\end{abstract}

Key words: breast cancer, pathogenesis, risk factor, prevention.

\section{Introduction}

Breast cancer is one of the most common cancers in women worldwide, accounting for approximately 570,000 deaths in 2015 . Over 1.5 million women $(25 \%$ of all women with cancer) are diagnosed with breast cancer every year throughout the world $[1,2]$. In America, it is estimated that $30 \%$ of all new cancer cases $(252,710)$ among women are breast cancer in 2017 [3]. Breast cancer is a metastatic cancer and can commonly transfer to distant organs such as the bone, liver, lung and brain, which mainly accounts for its incurability. Early diagnosis of the disease can lead to a good prognosis and a high survival rate. In North American, the 5-year relative survival rate of breast cancer patients is above $80 \%$ due to the timely detection of this disease [4]. Mammography is a widely used screening approach in the detecting of breast cancer and proved to help reduce the mortality effectively. Other screening methods, such as
Magnetic Resonance Imaging (MRI), which is more sensitive than mammography, have also been implemented and studied during the last decade [5]. There're numerous risk factors such as sex, aging, estrogen, family history, gene mutations and unhealthy lifestyle, which can increase the possibility of developing breast cancer [6]. Most breast cancer occur in women and the number of cases is 100 times higher in women than that in men [3]. Although the incidence rate of breast cancer in America increases year after year, the mortality rate decreases due to the widespread early screenings and advanced medical therapies. Biological therapies have been developed in recent years and proved to be beneficial for breast cancer. Here, we will focus on studies of the pathogenesis, related genes, risk factors and preventions of breast cancer over the past years. 


\section{Pathogenesis}

Breast tumors usually start from the ductal hyperproliferation, and then develop into benign tumors or even metastatic carcinomas after constantly stimulation by various carcinogenic factors. Tumor microenvironments such as the stromal influences or macrophages play vital roles in breast cancer initiation and progression. The mammary gland of rats could be induced to neoplasms when only the stroma was exposed to carcinogens, not the extracellular matrix or the epithelium $[7,8]$. Macrophages can generate a mutagenic inflammatory microenvironment, which can promote angiogenesis and enable cancer cells to escape immune rejection $[9,10]$. Different DNA methylation patterns have been observed between the normal and tumor-associated microenvironments, indicating that epigenetic modifications in the tumor microenvironment can promote the carcinogenesis [11,12]. Recently, a new subclass of malignant cells within tumors called the cancer stem cells (CSCs) are observed and associated with tumor initiation, escape and recurrence. This small population of cells, which may develop from stem cells or progenitor cells in normal tissues, have self-renewal abilities and are resistant to conventional therapies such as chemotherapy and radiotherapy [13-15]. Breast cancer stem cells (bCSCs) were first identified by Ai Hajj and even as few as 100 bCSCs could form new tumors in the immunocompromised mice [16]. bCSCs are more likely to originate from luminal epithelial progenitors rather than from basal stem cells [17]. Signaling pathways including Wnt, Notch, Hedgehog, p53, PI3K and HIF are involved in the self-renewal, proliferation and invasion of bCSCs [18-21]. However, more studies are needed to understand bCSCs and to develop novel strategies to directly eliminate the bCSCs.

There're two hypothetical theories for breast cancer initiation and progression: the cancer stem cell theory and the stochastic theory $[11,22]$. The cancer stem cell theory suggests that all tumor subtypes are derived from the same stem cells or transit-amplifying cells (progenitor cells). Acquired genetic and epigenetic mutations in stem cells or progenitor cells will lead to different tumor phenotypes (Figure 1A). The stochastic theory is that each tumor subtype is initiated from a single cell type (stem cell, progenitor cell, or differentiated cell) (Figure 1B). Random mutations can gradually accumulate in any breast cells, leading to their transformation into tumor cells when adequate mutations have accumulated. Although both theories are supported by plenty of data, neither can fully explain the origin of human breast cancer.

\section{Genes related to breast cancer}

Lots of genes have been identified in relation to breast cancer. Mutations and abnormal amplification of both oncogenes and anti-oncogenes play key roles in the processes of tumor initiation and progression.

\section{BRCA1/2}

Breast cancer associated gene 1 and 2 (BRCA1 and $B R C A 2)$ are two famous anti-oncogenes for breast cancer risk. BRCA1 and BRCA2 are located on chromosome 17q21 and 13q12, respectively. They both encode tumor suppressor proteins. BRCA1 deficiency leads to the dysregulation of cell cycle checkpoint, abnormal centrosome duplication, genetic instability and eventually apoptosis $[23,24]$. BRCA1 expression is repressed by "pocket proteins" such as p130, p107 and the retinoblastoma protein in an E2F-dependent manner. The BRCA1 gene has been shown to form a loop between the promoter, introns, and terminator regions, which regulates the expression of this gene via interactions with its own promoter $[25,26]$. BRCA2 protein regulates recombinational repair in DNA double-strand breaks by interacting with RAD51 and DMC1 [27,28]. BRCA2-associated breast cancers are more likely to be high-grade invasive ductal carcinomas, but with a luminal phenotype [29]. The risk of breast cancer could be increased greatly if an individual inherits deleterious mutations in either BRCA1 or BRCA2 genes. $B R C A 1 / 2$ mutations are inherited in an autosomal dominant manner even though the second allele is normal. Totally, about $20-25 \%$ of hereditary breast cancers and $5-10 \%$ of all breast cancers are caused by BRCA1/2 mutations [30,31]. A meta-analysis by Chen showed that the breast cancer risk ratio in women older than 70 years carrying BRCA1 or BRCA2 mutations was $57 \%$ and $49 \%$, respectively [32].

\section{HER2}

Human epidermal growth factor receptor 2, also known as c-erbB-2, is an important oncogene in breast cancer and located on the long arm of human chromosome 17 (17q12). The homologene in mice is $\mathrm{Neu}$ which was first identified in 3-methylcholanthrene induced rat neuroblastoma cells [33]. The expression of HER2 gene is activated mainly through the gene amplification and re-arrangement. HER2 protein is an epidermal growth factor receptor (EGFR) of tyrosine kinase family and form heterodimers with other ligand-bound EGFR family members such as Her3 and Her4, thus to activate downstream signaling pathways [34]. Knockout of HER2 in mouse models disrupts normal mammary duct formation. Overexpression of HER2, 
which is detected in about $20 \%$ of primary breast cancers, increases the number of cancer stem cells by PTEN/Akt/mTORC1 signaling, and indicates poor clinical outcomes $[35,36]$.

\section{Epidermal Growth Factor Receptor (EGFR)}

EGFR, also known as c-erbB-1 or Her1 in humans, is located on the short arm of chromosome 7 (7p12). The EGFR protein is a cell surface glycoprotein of tyrosine kinase family and is activated by binding to EGF, TGF- $a$, amphiregulin, betacellulin and so on. The downstream signaling pathways of EGFR including PI3K, Ras-Raf-MAPK and JNK are triggered to promote cell proliferation, cell invasion, angiogenesis and to protect cells against apoptosis $[37,38]$. Overexpression of EGFR is found in more than $30 \%$ of cases of the inflammatory breast cancer (IBC), a very aggressive subtype of breast cancer. Patients with EGFR-positive IBC have a poorer prognosis than those with EGFR-negative tumors $[39,40]$. More than half of triple-negative breast cancer (TNBC) cases, characterized by the absence of estrogen receptor (ER), progesterone receptor (PR) expression and HER2 amplification, also have EGFR overexpression [41]. Therefore, targeting the EGFR pathway might be a promising therapy for these malignant tumors.

\section{A stem cells, progenitor cells, Breast cancer "stem cells" or differentiated cells}

.

\section{Breast cancer subtypes}

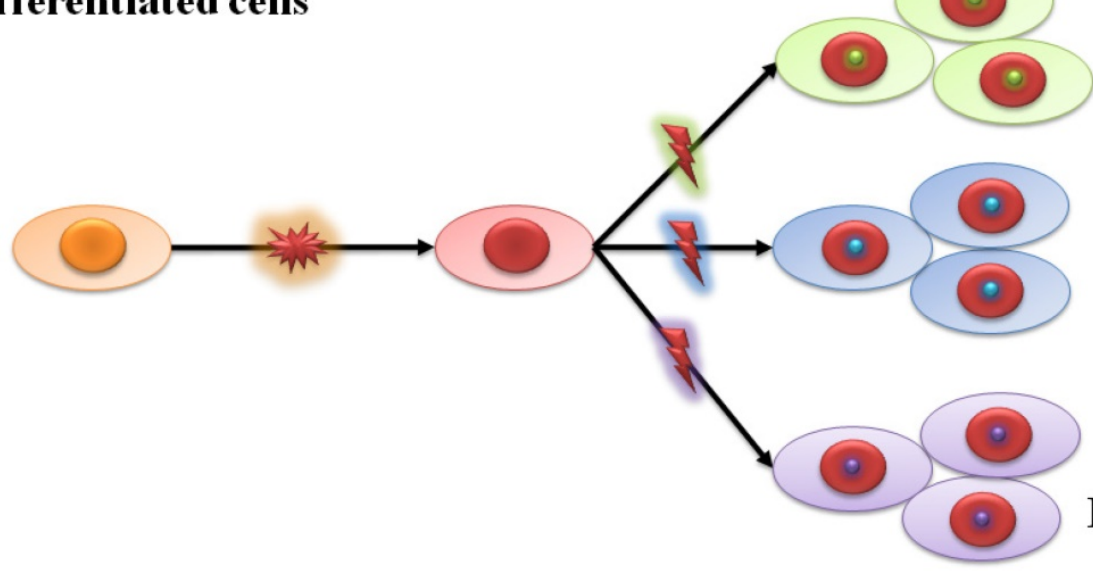

Basal-like tumors $\mathbf{E R}^{-}$, PR $^{-}$, HER2-

Luminal tumors $\mathbf{E R}^{+}, \mathbf{P R}^{+}$, HER2 $^{-}$

HER2 tumors $\mathrm{ER}^{-}, \mathrm{PR}^{-}, \mathrm{HER2}^{+}$

B

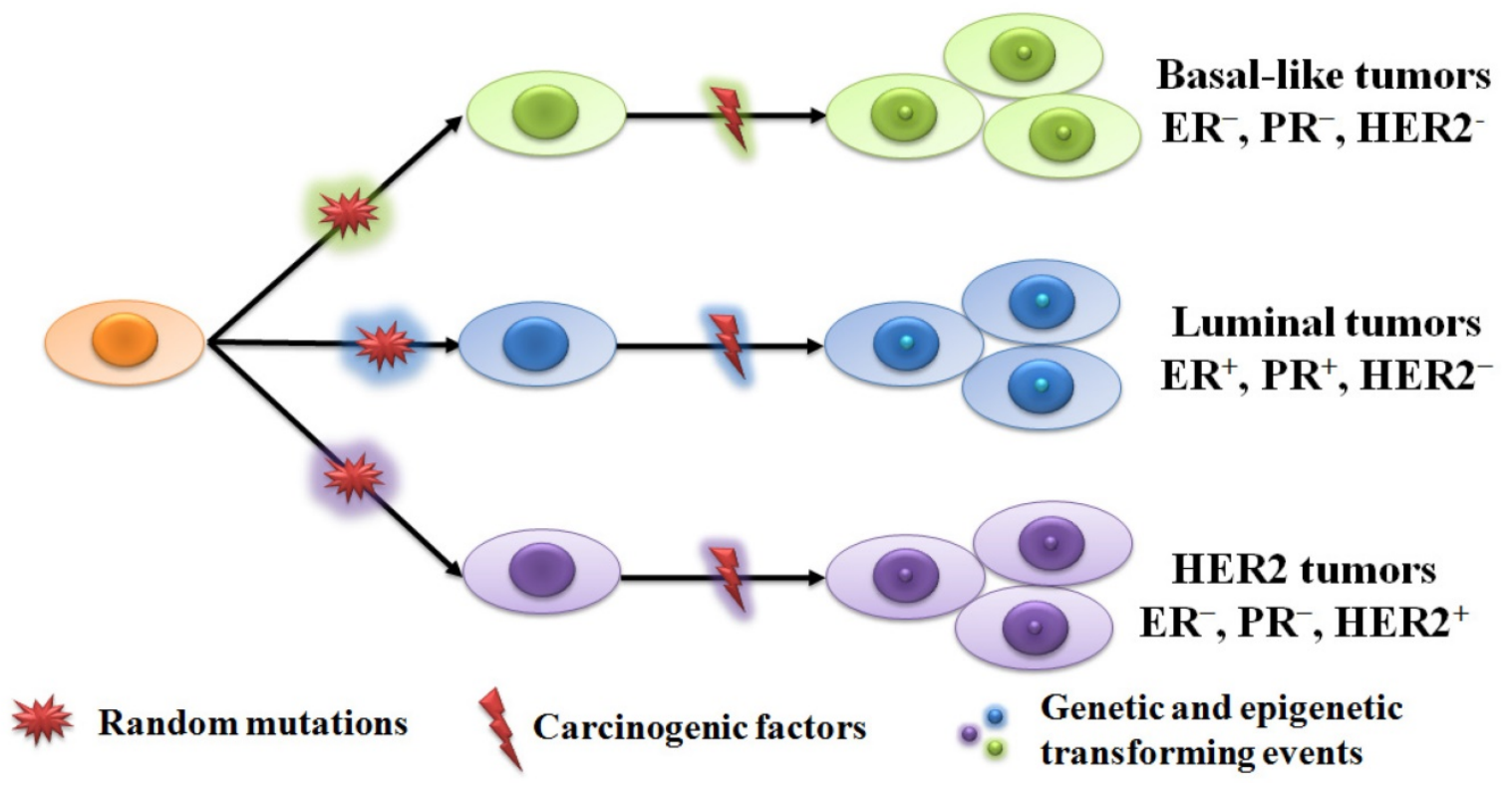

Figure 1. Two hypothetical theories of breast cancer initiation and progression. (A) All subtypes of tumor are derived from the same stem cells or progenitor cells. Different tumor phenotypes are then determined by subtype-specific transforming events. (B) Each tumor subtype is initiated from a single cell type (stem cell, progenitor cell, or differentiated cell). Random mutations can gradually accumulate in any breast cells, leading to their transformation into tumor cells when an adequate number of mutations have accumulated. 


\section{c-Myc}

This gene is located on the long arm of chromosome 8 (8q24) and encodes for the Myc protein, a transcription factor containing the bHLH/LZ (basic Helix-Loop-Helix Leucine Zipper) domain. Genome-wide screening shows that $15 \%$ of all genes are regulated by the Myc protein mainly through binding on the E-box consensus (CACGTG) and recruiting histone acetyltransferases (HATs) or DNA methyltransferases $[42,43]$. Some of the Myc-regulated genes such as MTA1, hTERT and PEG10 play vital roles in breast cancer initiation and progression. The overexpression of $\mathrm{c}-\mathrm{Myc}$ is predominantly observed in the high-grade, invasive stage of breast carcinomas, while no c-Myc amplification is detected in the benign tissues [44, 45].

\section{Other related genes}

\section{Ras}

There're three members in the Ras gene family: $\mathrm{H}$-ras, $\mathrm{K}$-ras and $\mathrm{N}$-ras, located on the chromosome of 11 (11p15), 12 (12p12) and $1(1 \mathrm{p} 22)$ respectively. The proteins encoded by these genes are extremely homologous, and they belong to the small guanosine triphosphate (GTP)-binding protein (G protein) superfamily [46]. Point mutations are commonly associated with the overexpression of these three human Ras genes, and most are missense mutations located at the coding domain for GTP binding. Though mutations of Ras proteins are infrequently in breast cancer $(<5 \%)$, the abnormality of Ras signal transduction pathway are observed in both benign and malignant mammary tissues [47]. H-ras can cooperate with B lymphoma moloney murine leukaemia virus insertion region-1 (BMI1) to promote proliferation, invasion, and to inhibit apoptosis in breast cancer cells [48]. H-ras overexpression is detected in both primary and advanced breast cancer patients, indicating a poor prognosis $[49,50]$.

\section{Risk factors}

A schematic diagram of risk factors is depicted in a pyramid-style structure (Figure 2).

\section{Aging}

Besides sex, aging is one of the most important risk factors of breast cancer, because the incidence of breast cancer is highly related to the increasing age. In 2016, approximately $99.3 \%$ and $71.2 \%$ of all breast cancer-associated deaths in America were reported in women over the age of 40 and 60, respectively [3]. Therefore, it is necessary to have a mammography screening ahead of time in women aged 40 or older.

\section{Family history}

Nearly a quarter of all breast cancer cases are related to family history [65]. Women, whose mother or sister has a breast cancer, are prone to this disease. A cohort study of over 113,000 women in UK demonstrated that women with one first-degree relative with breast cancer have a 1.75-fold higher risk of developing this disease than women without any affected relatives. Moreover, the risk becomes 2.5-fold or higher in women with two or more first-degree relatives with breast cancer [65]. The inherited susceptibility to breast cancer is partially attributed to the mutations of breast cancer related genes such as $B R C A 1$ and BRCA2.

Table 1. Additional genes associated with breast cancer

\begin{tabular}{|c|c|c|c|c|}
\hline Gene & Location & Function & $\begin{array}{l}\text { Abnormality in } \\
\text { Breast cancer }\end{array}$ & Ref. \\
\hline P53 & 17p13.1 & $\begin{array}{l}\text { tumor suppressor } \\
\text { gene }\end{array}$ & $\begin{array}{l}\text { Mutations in 30\% of } \\
\text { breast cancers }\end{array}$ & {$[51,52$} \\
\hline NME1 & $17 q 21.3$ & $\begin{array}{l}\text { metastasis-suppressor } \\
\text { gene }\end{array}$ & $\begin{array}{l}\text { SNP of NME1 gene } \\
\text { associated with } \\
\text { higher breast } \\
\text { cancer-specific } \\
\text { mortality (HR=1.4) } \\
\text { and patients with an } \\
\text { early-stage cancer } \\
(\mathrm{HR}=1.7)\end{array}$ & {$[53,54]$} \\
\hline RB1 & $13 q 14.2$ & $\begin{array}{l}\text { tumor suppressor } \\
\text { gene }\end{array}$ & $\begin{array}{l}\mathrm{Rb} 1 \text { inactivation in } \\
20-35 \% \text { of breast } \\
\text { cancers }\end{array}$ & {$[55,56]$} \\
\hline PTEN & $10 \mathrm{q} 23.3$ & $\begin{array}{l}\text { tumor suppressor } \\
\text { gene }\end{array}$ & $\begin{array}{l}\text { Loss of PTEN protein } \\
\text { expression in up to } \\
33 \% \text { of breast cancers }\end{array}$ & {$[57,58$} \\
\hline ATM & $11 q 22-q 23$ & $\begin{array}{l}\text { tumor suppressor } \\
\text { gene }\end{array}$ & $\begin{array}{l}\text { Mutation of ATM } \\
\text { increases the risk of } \\
\text { 2- to } 3 \text {-fold in } \\
\text { general, and 5- to } \\
\text { 9-fold in women } \\
\text { under age } 50\end{array}$ & [59] \\
\hline $\begin{array}{l}\text { CDH1 } \\
\text { (E-cadherin) }\end{array}$ & $16 \mathrm{q} 22.1$ & $\begin{array}{l}\text { tumor suppressor } \\
\text { gene }\end{array}$ & $\begin{array}{l}\text { Inactivation of CDH1 } \\
\text { in } 85 \% \text { of lobular } \\
\text { breast carcinomas }\end{array}$ & [60] \\
\hline FHIT & $3 p 14.2$ & $\begin{array}{l}\text { putative tumor } \\
\text { suppressor gene }\end{array}$ & $\begin{array}{l}\text { The rate of FHIT } \\
\text { hypermethylation in } \\
\text { breast cancer was } \\
8.4 \text {-fold higher than } \\
\text { that in normal breast } \\
\text { tissues }\end{array}$ & [61] \\
\hline Maspin & $18 \mathrm{q} 21.33$ & $\begin{array}{l}\text { tumor suppressor } \\
\text { gene }\end{array}$ & $\begin{array}{l}\text { Expression of } \\
\text { Maspin in 20-80\% } \\
\text { invasive breast } \\
\text { cancer }\end{array}$ & {$[62,63]$} \\
\hline PIK3CA & $3 q 26.3$ & oncogene & $\begin{array}{l}\text { Mutations in } 37 \% \text { of } \\
\text { the HR+/HER2- } \\
\text { metastatic and } 40 \% \\
\text { of early breast cancer }\end{array}$ & [56] \\
\hline $\begin{array}{l}\text { CCND1 } \\
\text { (Cyclin D1) }\end{array}$ & $11 q 13$ & oncogene & $\begin{array}{l}\text { Overexpression in } \\
50 \% \text { of breast tumors }\end{array}$ & [64] \\
\hline
\end{tabular}

Notes: SNP-Single Nucleotide Polymorphisms; HR-Hazard ratio

\section{Reproductive factors}

Reproductive factors such as early menarche, late menopause, late age at first pregnancy and low parity can increase the breast cancer risk. Each 1-year 
delay in menopause increases the risk of breast cancer by $3 \%$. Each 1-year delay in menarche or each additional birth decreases the risk of breast cancer by $5 \%$ or $10 \%$, respectively [66-68]. A recent Norwegian cohort study showed that a hazard ratio (HR) is 1.54 between late ( $\geq 35$ years) and early ( $<20$ years) age at first birth [69]. Reproductive factors are strongly associated with the ER status, with differences in the odds ratios (OR) between $\mathrm{ER}^{+}$and $\mathrm{ER}^{-}$breast cancer for parity (OR: 0.7 vs. 0.9 for $\geq 3$ births vs. nulliparae) and age at the first birth (OR: 1.6 vs. 1.2 for age $\geq 30$ vs. $<25$ years) [70].

\section{Estrogen}

Both endogenous and exogenous estrogens are associated with the risk of breast cancer. The endogenous estrogen is usually produced by the ovary in premenopausal women and ovariectomy can reduce the risk of breast cancer [71]. The main sources of exogenous estrogen are the oral contraceptives and the hormone replacement therapy (HRT). The oral contraceptives have been widely used since 1960s and the formulations have been upgraded to reduce side-effects. However, the OR is still higher than 1.5 for African American women and Iranian populations $[72,73]$. Nevertheless, oral contraceptives do not increase the risk of breast cancer in women who stop to use them for more than 10 years [66]. HRT involves the administration of exogenous estrogen or other hormones for the menopausal or postmenopausal women. A number of studies have shown that the use of HRT can increase the breast cancer risk. The Million Women Study in UK reported a relative risk (RR) of 1.66 between current users of HRT and those who never used it [74]. A cohort study of 22,929 women in Asia demonstrated HRs of 1.48 and 1.95 after HRT use for 4 and 8 years, respectively [75]. However, the risk of breast cancer has been shown to significantly decrease after two years of stopping HRT [76]. The recurrence rate is also high among breast cancer survivors who take HRT, and the HR for a new breast tumor is 3.6 [77]. Since the adverse effects of HRT were published in 2003 based on the Women's Health Initiative randomized controlled trial, the incidence rate of breast cancer in America has decreased by approximately $7 \%$ due to the reduction in the use of HRT [78].

\section{Lifestyle}

Modern lifestyles such as excessive alcohol consumption and too much dietary fat intake can increase the risk of breast cancer. Alcohol consumption can elevate the level of estrogen-related hormones in the blood and trigger the estrogen receptor pathways. A meta-analysis based on 53 epidemiological studies indicated that an intake of 35-44 grams of alcohol per day can increase the risk of breast cancer by $32 \%$, with a $7.1 \%$ increase in the RR for each additional 10 grams of alcohol per day $[79,80]$. Modern western diet contains too much fat and excess intake of fat, especially the saturated fat, is associated with mortality $(R R=1.3)$ and poor prognosis in breast cancer patients [81]. Although the relationship between smoking and breast cancer risk remains controversial, mutagens from cigarette smoke have been detected in the breast fluid from non-lactating women. The risk of breast cancer is also elevated in women who both smoke and drink $(R R=1.54)$ [82]. Up to now, accumulating evidences demonstrate that smoking, especially at an early age, has a higher risk on breast cancer occurrence [83-86].

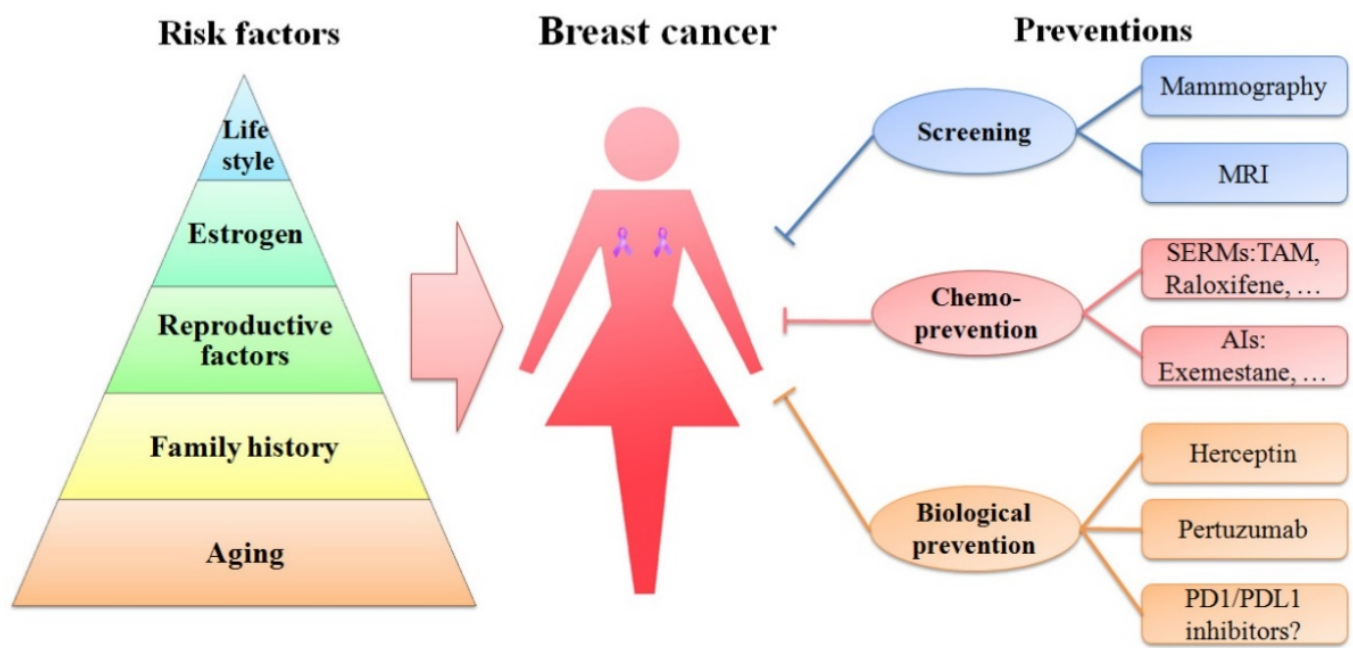

Figure 2. Schematic diagram of risk factors and preventions of breast cancer. Age, family history, reproductive factors, estrogen and life style are five important risk factors of breast cancer, represented in the pyramid chart. Screening (mammography and MRI), chemoprevention (with SERMs and Als) and biological prevention (using Herceptin and pertuzumab) are currently being used to prevent breast cancer. PDI/PDLl inhibitors are immunotherapy drugs and might be promising strategies in treating TNBC. 


\section{Preventions}

Thus far, great advances have been made in clinical and theoretical studies of breast cancer (Figure 2). The current prevention methods including screening, chemoprevention and biological prevention are more direct and effective than those in the past (Figure 2). The mortality of breast cancer has decreased. However, breast cancer is still the first leading cause of cancer death among females aged 20-59 years.

\section{Screening}

Not primary tumors but the tumor metastasis causes over $90 \%$ of cancer deaths [87]. However, if breast cancer is diagnosed as a primary tumor or at an early stage of metastasis, the breast tumor could be removed by surgery and the chemotherapy could work effectively. Early detection is the cornerstone of breast cancer prevention. Mammography is an effective screening method to use low energy $\mathrm{X}$-rays to obtain high-resolution images of the breast. The entire testing process only lasts for 20 minutes and it does not require any contrast-enhancing agent. Since the first recommendation for breast cancer screening by Professor Forrest, over 70\% of women (aged 50-74 years) in America have been undergone breast cancer screening via mammography every 2 years [88]. A meta-analysis of 11 randomized trials showed that women aged 50-70 years had a significant reduction in breast cancer mortality after screening with mammography (RR=0.81) [89]. However, the reduction in mortality rate was not significant in women aged 40-49 years [90]. These results indicate the importance of mammography screening programs. Although the reported percentage of overdiagnosis due to mammography varies across trials, overdiagnosis is undoubtedly a serious problem that cannot be ignored during breast cancer screening.

MRI is another widely used screening tool for breast cancer. It is more sensitive than mammography in high-risk women, especially in detecting the invasive ductal carcinoma [91]. Compared to mammography, MRI is not affected by the breast density and has advantages in detecting occult primary breast cancer, axillary nodal metastasis, residual tumors after neoadjuvant chemotherapy or other small tumors [92]. Advanced MRI scanners can measure tissues as small as $0.5 \mathrm{~mm}^{3}$. However, there's no identified benefit of MRI in patient outcomes such as in the rate of detection of ipsilateral breast tumor recurrence and contralateral breast cancer incidence. The specificity of MRI is much poorer than that of mammography, with detection rates ranging from
$37 \%$ to $100 \%$ [93]. Women with a family history of breast cancer have an approximately $20-25 \%$ or higher lifetime risk of breast cancer as demonstrated by MRI screening [94]. Each coin has two sides, and we should balance both the goodness and weakness. Considering its sensitivity, MRI may be a useful choice in high risk groups when the mammography results are normal.

\section{Chemoprevention}

The classical definition of chemotherapy by Sporn is "the use of pharmacologic or natural agents that inhibit the development of invasive breast cancer either by blocking the DNA damage that initiates carcinogenesis, or by arresting or reversing the progression of premalignant cells in which such damage has already occurred." [95]. Estrogen receptor is a major target for chemotherapy because more than $70 \%$ of breast cancers are ER-positive breast cancers. Selective estrogen receptor modulators (SERMs) and the aromatase inhibitors (AIs) are two major classes of anti-estrogen drugs. SERMs are compounds that act as either agonists or antagonists of estrogen receptors. One of the most famous SERMs is tamoxifen (TAM), which has been used to treat breast cancer for more than 30 years [96]. Regardless of the number, the scale, the related areas or the time lasting in the follow-up visit of TAM's research, this drug has no doubt the most abundant clinical data in SERMs. Meanwhile, TAM is used to treat all stages of breast cancer [97]. Many large-scale trials including the Breast Cancer Prevention Trial (NSABP-1), the Royal Marsden Prevention Trial, the Italian Prevention Trial and the International Breast Cancer Intervention Study (IBIS-I Trial) have shown that TAM could reduce the risk of both invasive and non-invasive breast cancer. Despite the differences in data collection and study design, all these trials have demonstrated greater than 30\% reduction in ER-positive breast cancer after 5 years treatment with TAM. However, no significant reduction has been observed in ER-negative tumors $[98,99]$. Nevertheless, there're some side-effects of TAM therapy. The risk of endometrial cancer, stroke, pulmonary embolism, and deep-vein thrombosis is increased in TAM-treated patients, and the risk is especially high among women older than 50 [100]. Therefore, TAM should be used individually by balancing between its toxicity and benefits.

Raloxifene, a second generation of SERMs with fewer side-effects than TAM, has been approved for the treatment of invasive breast cancer in postmenopausal women as well as osteoporosis and heart disease [101]. However, raloxifene shows no effect on ductal carcinoma in situ (DCIS) and lobular carcinoma in situ (LCIS). The Study of Tamoxifen and 
Raloxifene (STAR) trials showed that raloxifene was less effective than TAM [99]. Considering its less risk in endometrial cancers and thromboembolic complications, raloxifene is still a good therapeutic option for the invasive breast cancer. Several third generations of SERMs such as ospemifen, arzoxifene, lasofoxifene (LFX) and bazedoxifene (BZA) have also been discovered, but only BZA has reached the stage of clinical use. BZA has demonstrated potent effects in pre-clinical studies, but its efficacy was limited in pivotal clinical trials [102].

Recently, AIs are being used instead of TAM as the first line therapy in postmenopausal breast cancer patients. AIs reduce the plasma levels of estrogens by inhibiting aromatase, an enzyme that catalyzes the biosynthesis of estrogen from androgen [103]. There're two classes of AIs: steroidal inhibitors and non-steroidal inhibitors. Compared with exemestane, a steroidal inhibitor, non-steroidal inhibitors such as anastrozole and letrozole can bind to the enzyme's active site reversibly. However, these three third-generation AIs (exemestane, anastrozole and letrozole) have no significant differences in terms of efficacy in preventing breast cancer. Many trials such as the Italian Tamoxifen Anastrozole (ITA) trial, Intergroup Exemestane Study (IES), Austrian Breast and Colorectal Cancer Study Group (ABCSG-8), and the Breast International Group (BIG) 1-98 study have showed that in the adjuvant setting, AIs are more potent than TAM in reducing the incidence of breast cancer both as upfront monotherapy and after 2-3 years treatment with tamoxifen [104-110]. A 10-year ATAC trial study indicated fewer serious side-effects for anastrozole than for tamoxifen in postmenopausal women with early $\mathrm{ER}^{+}$breast cancer [111]. However, there're some limitations of AIs. Because AIs inhibit the biosynthesis of estrogen, they are typically used only in postmenopausal women. The main side-effect of AIs is that they can increase the risk of osteoporosis, which is a significant health threat for older women. Other side-effects, such as joint pain and stiffness, incidence of carpal tunnel syndrome or dysregulated lipid metabolism, have also been reported for AIs, but these side-effects have a lower impact on the quality of life of patients than endometrial cancer and thromboembolic complications associated with TAM treatment. Acquired resistance to AIs has been observed after prolonged treatment, which also occurs in the case of SERMs. Crosstalks between estrogen receptor pathway and several signaling pathways such as PI3K/Akt/mTOR and Ras/Raf/MEK/MAPK could lead cancer cells to be resistant to AIs [112]. The combination of AIs and inhibitors of the related signaling pathways may be a promising strategy for
AI-resistant patients.

\section{Biological prevention}

Recently, biological prevention, mainly known as the monoclonal antibodies for the breast cancer, has been developed to improve the quality of life in breast cancer patients. One of the major targets of these monoclonal antibodies is HER2. About $20-30 \%$ of all breast cancer cases exhibit HER2 protein overexpression or HER2 gene amplification [36]. Trastuzumab (Herceptin), a recombinant humanized monoclonal antibody, is the first HER2-targeted drug to be approved by the FDA. It can directly interact with the C-terminal portion of domain IV in the extracellular part of HER2 $[113,114]$. Up to now, the anti-tumor mechanism of trastuzumab has not been clearly elucidated. Some potential mechanisms may be that trastuzumab can suppress the growth and proliferation of cancer cells by recruiting ubiquitin to internalize and degrade HER2, by activating the immune system against cancer cells via a mechanism called antibody-dependent cell-mediated cytotoxicity (ADCC) or by inhibiting the MAPK and PI3K/Akt pathways [115-117]. Trastuzumab was initially used for treating metastatic breast cancer (MBC) and found to be efficacious as a single agent with an objective response rate (ORR) of $26 \%$. In vitro experiments have shown that trastuzumab has a synergistic effect with other anti-tumor drugs such as nimotuzumab, carboplatin, 4-hydroxycyclophosphamide, docetaxel and vinorelbine $[118,119]$. The HERA and TRAIN trials demonstrated that chemotherapy combined with adjuvant trastuzumab for 1 year could improve the disease-free survival in patients with HER2 ${ }^{+}$ breast cancer $(\mathrm{HR}=0.76)[120,121]$. A randomized phase II trial executed by Marty also showed that trastuzumab plus docetaxel was more efficacious than docetaxel alone in treating HER2-positive MBC, with the ORR of $50 \%$ versus $32 \%$ [122]. However, side-effects such as congestive heart failure and left ventricular ejection fraction (LVEF) decline were found in trastuzumab-treated patients [123].

Similar to trastuzumab, pertuzumab (Perjeta), another humanized monoclonal antibody, can bind to the extracellular portion of HER2 like trastuzumab. However, the binding domain is different [124]. Pertuzumab combined with trastuzumab and docetaxel has been approved for treating HER2-positive breast cancer. The pathologic complete response (pCR) rate, as well as invasive-disease-free survival rate, significantly increased in $\mathrm{HER}^{+}$tumors than those in HER- tumors (57.8\% versus $22.0 \%$ ) $[125,126]$. However, toxic side-effects like diarrhea and febrile neutropenia were common in pertuzumab-treated groups. 
Recently, immunotherapy becomes a hot spot in cancer therapy, and it shows great potential in clinical use. Programmed cell death 1 (PD1) is a membrane protein expressed in various immune cells, including $T$ cells, which can be engaged by its specific ligand to block the immune system. PD1 inhibitor drugs Nivolumab (Opdivo) and Pembrolizumab (Keytruda) were approved for the treatment of several solid tumors such as metastatic melanoma and non-small cell lung cancer. In the KEYNOTE-012 study, pembrolizumab was found to be effective in 27 TNBC patients with a clinical benefit rate of $20 \%$ [127]. Programmed cell death receptor ligand 1 (PDL1), a ligand of PD1, is detected in $20 \%$ of TNBC and in $50 \%$ of all breast cancers [128]. PDL1 inhibitor drug Atezolizumab (Tecentriq) exhibits a $19 \%$ of objective response rate in a phase I study including 54 TNBC patients [129]. Though TNBC patients typically have poor clinical outcomes, anti-PD1/PDL1 drugs might be promising strategies for treating this subtype of breast cancer.

\section{Conclusion and further directions}

Breast cancer is the most frequently diagnosed cancer in women across 140 countries [1]. Approximately 1 in 8 women worldwide have a lifetime risk of developing breast cancer [130]. Breast cancer develops through a multistep process, and the pathogenesis of this disease has not yet been elucidated. In the last decade, the tumor microenvironment and breast CSCs have been identified as contributors to breast tumorigenesis. Breast cancer is also influenced by genetic and environmental factors. Targeted prevention strategies against these risk factors should be taken ahead of time.

Although the incidence rate of breast cancer is high in developed countries, the fact which we can't ignore is that almost half of the breast cancer cases and over half of deaths occur in developing countries. The 5-year relative survival rates of breast cancer varied widely in developed and developing countries. The rate is over $80 \%$ in North American and Japan, but below 40\% in Africa countries like Algeria. Breast cancer is a preventable disease, and there are adequate medical resources available in developed countries, which can protect against this disease, such as annual mammography screening or the daily use of chemopreventative drugs. These may be attributable for the higher survival rate of breast cancer patients in developed countries than that in middle-income or low-income countries. Considering the financial burden of developing countries, the clinical breast examination is an effective way to diagnose breast cancer in the early stage. Moreover, if women are educated about breast cancer, breast self-examination may be a simple, economical and motivated method to prevent this disease. People know their own bodies more clearly than any doctors. However, most of the women in developing countries don't realize the importance of breast cancer prevention. Therefore, in these countries, more attention should be focused on breast health promotion ahead of clinical treatment.

Nowadays, with the reduction in the cost of DNA sequencing, individual genome sequencing may be affordable by middle-class populations, and this could be a new method in preventing breast cancer. If a woman have a family history of breast cancer, it is wise to do a screen especially on hereditary cancer susceptibility genes such as BRCA1 or BRCA2. The risk of breast cancer could then be evaluated based on the screening results and prevention advice could be offered personally. Individual genome sequencing may be a mainstream in the future for prevention of breast cancer as well as other hereditary disease. Additionally, risk factors should be taken more seriously either in normal or high-risk women. Environmental factors such as the exogenous estrogen intake, alcohol abuse and excess dietary fat consumption could be avoided to minimize breast cancer risk. Though some risk facts such as aging and reproductive factors are inevitable, measures should be taken ahead of time to reduce the risk. In the modern world, many people spend countless hours sitting at tables. People are more engaged in mental work rather than in physical work. However, physically active women have a $25 \%$ lower risk of breast cancer on average than women who are less active [131]. Regular physical exercise may be a convenient and inexpensive way to prevent breast cancer in women from both developed and developing countries.

Although traditional film mammography has limitations in detecting dense breasts, digital mammography can overcome this deficiency. It can capture images directly through an X-ray-sensitive detector and the digital data are analyzed in the computer. The Digital Mammographic Imaging Screening Trial (DMIST) showed that digital mammography had a better diagnostic performance than film mammography in pre- and perimenopausal women with dense breasts who were younger than 50 years of age. With advancements in digital technology, high-resolution digital mammography may replace film mammography in the future [132]. What's more, both mammography and MRI screening for a large population of women are expensive and only countries with good health insurance systems can offer these services. Direct breast ultrasonography, an adjuvant technique method to 
mammography and MRI, is less expensive and could be used widely in low- and middle-income countries. The ultrasonography is much more accurate if the operator is skilled and experienced.

Although great progress has been made in breast cancer prevention in the last decade, there is still a lack of effective therapies against TNBC. TNBC tends to have a higher relapse risk and is more aggressive than other subtypes, resulting in a poor 5-year survival rate [133]. Due to the absence of ER/PR expression and HER2 amplification, drugs targeted against these three receptors are useless in TNBC. In the last decade, several potential biomarkers in TNBC such as EGFR, androgen receptor (AR), PARP and mTOR, and microRNA-based biomarkers, such as miR-374b-5p and miR-629-3p have been identified and explored for targeted therapies [134-136]. The EGFR-inhibitor cetuximab combined with cisplatin increased the progression-free survival from 1.5 to 3.7 months, and the overall survival from 9.4 to 12.9 months in a phase II clinical trial [137]. Expressions of AR is observed in $30 \%$ of TNBC patients, and the AR inhibitor bicalutaminde showed a clinical benefit rate of $19 \%$ in ER/PR negative breast cancer patients in a phase II study $[138,139]$. PARP-inhibitor iniparib plus chemotherapy were also tested and showed promising results in phase I and II clinical trials. However, the phase III clinical trial failed with the lack of improvement in progression-free survival and overall survival [140]. Targeting the PI3K/AKT/mTOR pathway was thought to be an effective strategy to treat TNBC recently, and the mTOR inhibitor everolimus combined with doxorubicin and bevacizumab increased the objective response rate but not the clinical benefit rate [141]. Although many biomarker-based trials have been performed in TNBC, none has been successful finally. One of the main reasons for this failure could be the heterogeneity of TNBC. More work is needed to elucidate tumor heterogeneity, and the discovery of a robust biomarker regardless of tumor heterogeneity may be a breakthrough in TNBC treatment. Immunotherapy agents such as anti-PD1/PDL1 drugs will also shed light on treating TNBC.

In summary, breast cancer is preventable. Reducing risk factors and taking chemoprevention are two main measures to prevent breast cancer. However, there's a long way to go in creating public breast cancer awareness. Only $4.1 \%$ of high-risk women are willing to take chemoprevention drugs [142]. The fear of adverse effects and lack of understanding of breast cancer might be attributable for this unwillingness. Although, the Gail model or the IBIS model is widely used for determining the risk of breast cancer based on a woman's age, family history, race and reproductive factors, we still lack a reliable strategy to exactly evaluate the risk ratio of breast cancer. With improvements in sequencing technology, individual genome sequencing may be a powerful method to evaluate the risk of breast cancer. Better medicines with less adverse effects and a favorable risk-benefit ratio need to be developed in the future.

\section{Acknowledgements}

We would like to thank Dr. Yan-Ling Wu for her advice on this paper. This work is supported by Zhejiang Provincial Natural Science Foundation of China under Grant No. LQ15C040001 and LY18H190003, Social Development Project of Public Welfare Technology Research in Zhejiang Province (LGF18H100002), and Zhejiang Provincial Foundation for Scientific Research in Medicine and Health (2015RCB009).

\section{Competing Interests}

The authors have declared that no competing interest exists.

\section{References}

1. Stewart BW, and Wild CP. World Cancer Report 2014. Geneva, Switzerland: WHO Press; 2014

2. [Internet] WHO: Geneva, Switzerland. Breast cancer. http://www.who.int/cancer/prevention/diagnosis-screening/breast-cancer /en/

3. Siegel RL, Miller KD, and Jemal A. Cancer Statistics, 2017. CA Cancer J Clin. 2017; 67: 7-30

4. DeSantis CE, Fedewa SA, Goding Sauer A, et al. Breast cancer statistics, 2015: Convergence of incidence rates between black and white women. CA Cancer J Clin. 2016; 66: 31-42.

5. Drukteinis JS, Mooney BP, Flowers CI, et al. Beyond mammography: new frontiers in breast cancer screening. Am J Med. 2013; 126: 472-479.

6. Majeed W, Aslam B, Javed I, et al. Breast cancer: major risk factors and recent developments in treatment. APJCP. 2014; 15: 3353-3358.

7. Maffini MV, Soto AM, Calabro JM, et al. The stroma as a crucial target in rat mammary gland carcinogenesis. J Cell Sci. 2004; 117: 1495-1502.

8. Sonnenschein C, and Soto AM. Carcinogenesis explained within the context of a theory of organisms. Progress in biophysics and molecular biology. 2016; 122: 70-76.

9. Qian BZ, and Pollard JW. Macrophage diversity enhances tumor progression and metastasis. Cell. 2010; 141: 39-51.

10. Dumars C, Ngyuen JM, Gaultier A, et al. Dysregulation of macrophage polarization is associated with the metastatic process in osteosarcoma. Oncotarget. 2016; 7: 78343-78354.

11. Polyak K. Breast cancer: origins and evolution. J Clin Invest. 2007; 117: 3155-3163.

12. Basse $\mathrm{C}$, and Arock $\mathrm{M}$. The increasing roles of epigenetics in breast cancer: Implications for pathogenicity, biomarkers, prevention and treatment. Int J Cancer. 2015; 137: 2785-2794.

13. Baumann M, Krause M, and Hill R. Exploring the role of cancer stem cells in radioresistance. Nat Rev Cancer. 2008; 8: 545-554.

14. Smalley M, Piggott L, and Clarkson R. Breast cancer stem cells: obstacles to therapy. Cancer Lett. 2013; 338: 57-62.

15. Zhang M, Lee AV, and Rosen JM. The Cellular Origin and Evolution of Breast Cancer. Cold Spring Harbor perspectives in medicine. 2017; 7: a027128.

16. Al-Hajj M, Wicha MS, Benito-Hernandez A, et al. Prospective identification of tumorigenic breast cancer cells. Proc Natl Acad Sci U S A. 2003; 100: 3983-3988.

17. Molyneux G, Geyer FC, Magnay FA, et al. BRCA1 basal-like breast cancers originate from luminal epithelial progenitors and not from basal stem cells. Cell Stem Cell. 2010; 7: 403-417.

18. Valenti G, Quinn HM, Heynen G, et al. Cancer Stem Cells Regulate Cancer-Associated Fibroblasts via Activation of Hedgehog Signaling in Mammary Gland Tumors. Cancer Res. 2017; 77: 2134-2147.

19. El Helou R, Pinna G, Cabaud O, et al. miR-600 Acts as a Bimodal Switch that Regulates Breast Cancer Stem Cell Fate through WNT Signaling. Cell reports. 2017; 18: 2256-2268. 
20. Shukla G, Khera HK, Srivastava AK, et al. Therapeutic Potential, Challenges and Future Perspective of Cancer Stem Cells in Translational Oncology: A Critical Review. Current stem cell research \& therapy. 2017; 12: 207-224.

21. Kasper M, Jaks V, Fiaschi $M$, et al. Hedgehog signalling in breast cancer. Carcinogenesis. 2009; 30: 903-911.

22. Sgroi DC. Preinvasive breast cancer. Annu Rev Pathol. 2010; 5: 193-221.

23. Deng CX. BRCA1: cell cycle checkpoint, genetic instability, DNA damage response and cancer evolution. Nucleic Acids Res. 2006; 34: 1416-1426.

24. Dine J, and Deng CX. Mouse models of BRCA1 and their application to breast cancer research. Cancer Metastasis Rev. 2013; 32: 25-37.

25. Tan-Wong SM, French JD, Proudfoo NJ, et al. Dynamic interactions between the promoter and terminator regions of the mammalian BRCA1 gene. P Natl Acad Sci USA. 2008; 105: 5160-5165.

26. Hegan DC, Lu Y, Stachelek GC, et al. Inhibition of poly(ADP-ribose) polymerase down-regulates BRCA1 and RAD51 in a pathway mediated by E2F4 and p130. Proc Natl Acad Sci U S A. 2010; 107: 2201-2206.

27. Sanchez H, Paul MW, Grosbart M, et al. Architectural plasticity of human BRCA2-RAD51 complexes in DNA break repair. Nucleic Acids Res. 2017; 45: $4507-4518$.

28. Martinez JS, von Nicolai C, Kim T, et al. BRCA2 regulates DMC1-mediated recombination through the BRC repeats. Proc Natl Acad Sci U S A. 2016; 113: 3515-3520.

29. Bane AL, Beck JC, Bleiweiss I, et al. BRCA2 mutation-associated breast cancers exhibit a distinguishing phenotype based on morphology and molecular profiles from tissue microarrays. Am J Surg Pathol. 2007; 31: 121-128.

30. Balmana J, Diez O, Rubio IT, et al. BRCA in breast cancer: ESMO Clinical Practice Guidelines. Ann Oncol. 2011; 22 Suppl 6: 31-34.

31. Paluch-Shimon S, Cardoso F, Sessa C, et al. Prevention and screening in BRCA mutation carriers and other breast/ovarian hereditary cancer syndromes: ESMO Clinical Practice Guidelines for cancer prevention and screening. Ann Oncol. 2016; 27: 103-110.

32. Chen S, and Parmigiani G. Meta-analysis of BRCA1 and BRCA2 penetrance. J Clin Oncol. 2007; 25: 1329-1333

33. Shih C, Padhy LC, Murray M, et al. Transforming genes of carcinomas and neuroblastomas introduced into mouse fibroblasts. Nature. 1981; 290: 261-264.

34. Harbeck N, and Gnant M. Breast cancer. The Lancet. 2017; 389: 1134-1150.

35. Davis NM, Sokolosky M, Stadelman $K$, et al. Deregulation of the EGFR/PI3K/PTEN/Akt/mTORC1 pathway in breast cancer: possibilities for therapeutic intervention. Oncotarget. 2014; 5: 4603-4650.

36. Elizalde PV, Cordo Russo RI, Chervo MF, et al. ErbB-2 nuclear function in breast cancer growth, metastasis and resistance to therapy. Endocr Relat Cancer. 2016; 23: 243-257.

37. Appert-Collin A, Hubert P, Cremel G, et al. Role of ErbB Receptors in Cancer Cell Migration and Invasion. Frontiers in pharmacology. 2015; 6: 283.

38. Ali R, and Wendt MK. The paradoxical functions of EGFR during breast cancer progression. Signal transduction and targeted therapy. 2017; 2: 16042.

39. Alanazi IO, and Khan Z. Understanding EGFR Signaling in Breast Cancer and Breast Cancer Stem Cells: Overexpression and Therapeutic Implications. Asian Pacific journal of cancer prevention : APJCP. 2016; 17: 445-453.

40. Zhang D, LaFortune TA, Krishnamurthy S, et al. Epidermal growth factor receptor tyrosine kinase inhibitor reverses mesenchymal to epithelial phenotype and inhibits metastasis in inflammatory breast cancer. Clin Cancer Res. 2009; 15: 6639-6648.

41. Kim A, Jang MH, Lee SJ, et al. Mutations of the Epidermal Growth Factor Receptor Gene in Triple-Negative Breast Cancer. Journal of breast cancer. 2017; 20: 150-159.

42. Green AR, Aleskandarany MA, Agarwal D, et al. MYC functions are specific in biological subtypes of breast cancer and confers resistance to endocrine therapy in luminal tumours. Br J Cancer. 2016; 114: 917-928.

43. Poole CJ, and van Riggelen J. MYC-Master Regulator of the Cancer Epigenome and Transcriptome. Genes. 2017; 8: 142

44. Chen Y, and Olopade OI. MYC in breast tumor progression. Expert Rev Anticancer Ther. 2008; 8: 1689-1698.

45. Jung M, Russell AJ, Liu B, et al. A Myc Activity Signature Predicts Poor Clinical Outcomes in Myc-Associated Cancers. Cancer Res. 2017: 77: 971-981.

46. Pylayeva-Gupta Y, Grabocka E, and Bar-Sagi D. RAS oncogenes: weaving a tumorigenic web. Nat Rev Cancer. 2011; 11: 761-774.

47. Siewertsz van Reesema LL, Lee MP, Zheleva V, et al. RAS pathway biomarkers for breast cancer prognosis. Clinical laboratory international. 2016; 40: $18-23$.

48. Hoenerhoff MJ, Chu I, Barkan D, et al. BMI1 cooperates with H-RAS to induce an aggressive breast cancer phenotype with brain metastases. Oncogene. 2009; 28: 3022-3032.

49. Fernandez-Medarde A, and Santos E. Ras in cancer and developmental diseases. Genes \& cancer. 2011; 2: 344-358.

50. Ray A, and Ray BK. Induction of Ras by SAF-1/MAZ through a feed-forward loop promotes angiogenesis in breast cancer. Cancer medicine. 2015; 4: 224-234.

51. Varna M, Bousquet G, Plassa LF, et al. TP53 status and response to treatment in breast cancers. J Biomed Biotechnol. 2011; 2011: 284584.

52. Hientz K, Mohr A, Bhakta-Guha D, et al. The role of p53 in cancer drug resistance and targeted chemotherapy. Oncotarget. 2017; 8: 8921-8946.

53. Roberts MR, Sucheston-Campbell LE, Zirpoli GR, et al. Single nucleotide variants in metastasis-related genes are associated with breast cancer risk, by lymph node involvement and estrogen receptor status, in women with European and African ancestry. Molecular carcinogenesis. 2017; 56: 1000-1009.

54. Qu S, Long J, Cai Q, et al. Genetic polymorphisms of metastasis suppressor gene NME1 and breast cancer survival. Clin Cancer Res. 2008; 14: 4787-4793.

55. Cheng L, Zhou Z, Flesken-Nikitin A, et al. Rb inactivation accelerates neoplastic growth and substitutes for recurrent amplification of cIAP1, cIAP2 and Yap1 in sporadic mammary carcinoma associated with p53 deficiency. Oncogene. 2010; 29: 5700-5711.

56. Lefebvre C, Bachelot T, Filleron T, et al. Mutational Profile of Metastatic Breast Cancers: A Retrospective Analysis. PLoS medicine. 2016; 13: e1002201.

57. Loibl S, Darb-Esfahani S, Huober J, et al. Integrated Analysis of PTEN and p4EBP1 Protein Expression as Predictors for pCR in HER2-Positive Breast Cancer. Clin Cancer Res. 2016; 22: 2675-2683.

58. Hernandez-Aya LF, and Gonzalez-Angulo AM. Targeting the phosphatidylinositol 3-kinase signaling pathway in breast cancer. The oncologist. 2011; 16: 404-414.

59. Choi M, Kipps T, and Kurzrock R. ATM Mutations in Cancer: Therapeutic Implications. Molecular cancer therapeutics. 2016; 15: 1781-1791.

60. Desmedt C, Zoppoli G, Gundem G, et al. Genomic Characterization of Primary Invasive Lobular Breast Cancer. J Clin Oncol. 2016; 34: 1872-1881.

61. Su Y, Wang X, Li J, et al. The clinicopathological significance and drug target potential of FHIT in breast cancer, a meta-analysis and literature review. Drug design, development and therapy. 2015; 9: 5439-5445.

62. Berardi R, Morgese F, Onofri A, et al. Role of maspin in cancer. Clinical and translational medicine. 2013; 2: 8

63. Dabiri S, Moeini Aghtaei M, Shahryari J, et al. Maspin Gene Expression in Invasive Ductal Carcinoma of Breast. Iranian journal of pathology. 2016; 11: 104-111.

64. Inoue K, and Fry EA. Aberrant expression of cyclin D1 in cancer. Signal transduction insights. 2015; 4: 1-13.

65. Brewer HR, Jones ME, Schoemaker MJ, et al. Family history and risk of breast cancer: an analysis accounting for family structure. Breast Cancer Res Treat. 2017; 165: 193-200

66. Washbrook E. Risk factors and epidemiology of breast cancer. Women's Health Medicine. 2006; 3: 8-14.

67. Horn J, and Vatten LJ. Reproductive and hormonal risk factors of breast cancer: a historical perspective. International journal of women's health. 2017; 9: 265-272.

68. Dall GV, and Britt KL. Estrogen Effects on the Mammary Gland in Early and Late Life and Breast Cancer Risk. Front Oncol. 2017; 7: 110.

69. Horn J, Asvold BO, Opdahl S, et al. Reproductive factors and the risk of breast cancer in old age: a Norwegian cohort study. Breast Cancer Res Treat. 2013; 139: 237-243.

70. Rosato V, Bosetti C, Negri E, et al. Reproductive and hormonal factors, family history, and breast cancer according to the hormonal receptor status. Eur J Cancer Prev. 2014; 23: 412-417.

71. Endogenous H, Breast Cancer Collaborative G, Key TJ, et al. Sex hormones and risk of breast cancer in premenopausal women: a collaborative reanalysis of individual participant data from seven prospective studies. Lancet Oncol. 2013; 14: 1009-1019.

72. Soroush A, Farshchian N, Komasi S, et al. The Role of Oral Contraceptive Pills on Increased Risk of Breast Cancer in Iranian Populations: A Meta-analysis. Journal of cancer prevention. 2016; 21: 294-301.

73. Bethea TN, Rosenberg L, Hong CC, et al. A case-control analysis of oral contraceptive use and breast cancer subtypes in the African American Breast Cancer Epidemiology and Risk Consortium. Breast Cancer Res. 2015; 17: 22.

74. Beral V. Breast cancer and hormone-replacement therapy in the Million Women Study. Lancet. 2003; 362: 419-427.

75. Liu J-Y, Chen T-J, and Hwang S-J. The Risk of Breast Cancer in Women Using Menopausal Hormone Replacement Therapy in Taiwan. International journal of environmental research and public health. 2016; 13: 482.

76. Narod SA. Hormone replacement therapy and the risk of breast cancer. Nature reviews. Clinical oncology. 2011; 8: 669-676.

77. Fahlen M, Fornander $\mathrm{T}$, Johansson $\mathrm{H}$, et al. Hormone replacement therapy after breast cancer: 10 year follow up of the Stockholm randomised trial. Eur J Cancer. 2013; 49: 52-59.

78. Ravdin PM, Cronin KA, Howlader N, et al. The decrease in breast-cancer incidence in 2003 in the United States. N Engl J Med. 2007; 356: 1670-1674.

79. Hamajima N, Hirose $K$, Tajima $K$, et al. Alcohol, tobacco and breast cancer--collaborative reanalysis of individual data from 53 epidemiological studies, including 58,515 women with breast cancer and 95,067 women without the disease. Br J Cancer. 2002; 87: 1234-1245.

80. Jung S, Wang M, Anderson K, et al. Alcohol consumption and breast cancer risk by estrogen receptor status: in a pooled analysis of 20 studies. International journal of epidemiology. 2016; 45: 916-928.

81. Makarem N, Chandran U, Bandera EV, et al. Dietary fat in breast cancer survival. Annu Rev Nutr. 2013; 33: 319-348.

82. Knight JA, Fan J, Malone KE, et al. Alcohol consumption and cigarette smoking in combination: A predictor of contralateral breast cancer risk in the WECARE study. Int J Cancer. 2017; 141: 916-924.

83. Catsburg $\mathrm{C}$, Miller $\mathrm{AB}$, and Rohan TE. Active cigarette smoking and risk of breast cancer. Int J Cancer. 2015; 136: 2204-2209.

84. Gaudet MM, Carter BD, Brinton LA, et al. Pooled analysis of active cigarette smoking and invasive breast cancer risk in 14 cohort studies. International journal of epidemiology. 2017; 46: 881-893. 
85. McKenzie F, Ellison-Loschmann L, Jeffreys M, et al. Cigarette smoking and risk of breast cancer in a New Zealand multi-ethnic case-control study. PLoS One. 2013; 8: e63132.

86. Kispert S, and McHowat J. Recent insights into cigarette smoking as a lifestyle risk factor for breast cancer. Breast Cancer : Targets and Therapy. 2017; 9: 127-132.

87. Valastyan S, and Weinberg RA. Tumor metastasis: molecular insights and evolving paradigms. Cell. 2011; 147: 275-292.

88. Prevention CfDCa. Cancer screening - United States, 2010. Morb Mortal Wkly Rep. 2012; 61: 41-45.

89. The benefits and harms of breast cancer screening: an independent review. Lancet. 2012; 380: 1778-1786.

90. van den Ende C, Oordt-Speets AM, Vroling H, et al. Benefits and harms of breast cancer screening with mammography in women aged 40-49 years: A systematic review. Int J Cancer. 2017; 141: 1295-1306.

91. Greenwood HI, Heller SL, Kim S, et al. Ductal Carcinoma in Situ of the Breasts: Review of MR Imaging Features. Radiographics. 2013; 33: 1569-1588.

92. Morrow M, Waters J, and Morris E. MRI for breast cancer screening, diagnosis, and treatment. Lancet. 2011; 378: 1804-1811.

93. Enriquez L, and Listinsky J. Role of MRI in breast cancer management. Cleve Clin J Med. 2009; 76: 525-532.

94. Saslow D, Boetes C, Burke W, et al. American Cancer Society guidelines for breast screening with MRI as an adjunct to mammography. CA Cancer J Clin. 2007; 57: 75-89.

95. Sporn MB. Approaches to prevention of epithelial cancer during the preneoplastic period. Cancer Res. 1976; 36: 2699-2702

96. Bozovic-Spasojevic I, Azambuja E, McCaskill-Stevens W, et al. Chemoprevention for breast cancer. Cancer Treat Rev. 2012; 38: 329-339.

97. Nagini S. Breast Cancer: Current Molecular Therapeutic Targets and New Players. Anti-cancer agents in medicinal chemistry. 2017; 17: 152-163.

98. Cuzick J, Powles T, Veronesi U, et al. Overview of the main outcomes in breast-cancer prevention trials. Lancet. 2003; 361: 296-300.

99. Cuzick J, Sestak I, Bonanni B, et al. Selective oestrogen receptor modulators in prevention of breast cancer: an updated meta-analysis of individual participant data. Lancet. 2013; 381: 1827-1834.

100. Yang Y, Pan W, Tang X, et al. A meta-analysis of randomized controlled trials comparing the efficacy and safety of anastrozole versus tamoxifen for breast cancer. Oncotarget. 2017; 18: 48362-48374.

101. Barrett-Connor E, Mosca L, Collins P, et al. Effects of raloxifene on cardiovascular events and breast cancer in postmenopausal women. $\mathrm{N}$ Engl J Med. 2006; 355: 125-137.

102. Coronado Martin PJ, and Calaf Alsina J. Third generation selective estrogen receptor modulators benefits beyond bone: effects on breast. Med Clin (Barc). 2013; 140: 217-222.

103. Hiscox S, Davies EL, and Barrett-Lee P. Aromatase inhibitors in breast cancer. Maturitas. 2009; 63: 275-279.

104. Dowsett M, Cuzick J, Ingle J, et al. Meta-analysis of breast cancer outcomes in adjuvant trials of aromatase inhibitors versus tamoxifen. J Clin Oncol. 2010; 28 : 509-518.

105. Goss PE, Ingle JN, Ales-Martinez JE, et al. Exemestane for breast-cancer prevention in postmenopausal women. N Engl J Med. 2011; 364: 2381-2391.

106. Boccardo F, Guglielmini P, Bordonaro R, et al. Switching to anastrozole versus continued tamoxifen treatment of early breast cancer: long term results of the Italian Tamoxifen Anastrozole trial. Eur J Cancer. 2013; 49: 1546-1554.

107. Bliss JM, Kilburn LS, Coleman RE, et al. Disease-related outcomes with long-term follow-up: an updated analysis of the intergroup exemestane study. J Clin Oncol. 2012; 30: 709-717.

108. Dubsky PC, Jakesz R, Mlineritsch B, et al. Tamoxifen and anastrozole as a sequencing strategy: a randomized controlled trial in postmenopausal patients with endocrine-responsive early breast cancer from the Austrian Breast and Colorectal Cancer Study Group. J Clin Oncol. 2012; 30: 722-728.

109. Regan MM, Neven P, Giobbie-Hurder A, et al. Assessment of letrozole and tamoxifen alone and in sequence for postmenopausal women with steroid hormone receptor-positive breast cancer: the BIG 1-98 randomised clinical trial at 8.1 years median follow-up. Lancet Oncol. 2011; 12: 1101-1108.

110. Forbes JF, Cuzick J, Buzdar A, et al. Effect of anastrozole and tamoxifen as adjuvant treatment for early-stage breast cancer: 100-month analysis of the ATAC trial. Lancet Oncol. 2008; 9: 45-53.

111. Cuzick J, Sestak I, Baum M, et al. Effect of anastrozole and tamoxifen as adjuvant treatment for early-stage breast cancer: 10-year analysis of the ATAC trial. Lancet Oncol. 2010; 11: 1135-1141.

112. Lonning PE, and Eikesdal HP. Aromatase inhibition 2013: clinical state of the art and questions that remain to be solved. Endocr Relat Cancer. 2013; 20: R183-201.

113. Cho HS, Mason K, Ramyar KX, et al. Structure of the extracellular region of HER2 alone and in complex with the Herceptin Fab. Nature. 2003; 421: 756-760.

114. Nielsen DL, Andersson M, and Kamby C. HER2-targeted therapy in breast cancer. Monoclonal antibodies and tyrosine kinase inhibitors. Cancer Treat Rev. 2009; 35: 121-136.

115. Junttila TT, Akita RW, Parsons K, et al. Ligand-independent HER2/HER3/PI3K complex is disrupted by trastuzumab and is effectively inhibited by the PI3K inhibitor GDC-0941. Cancer Cell. 2009; 15: 429-440.

116. Vu T, and Claret FX. Trastuzumab: updated mechanisms of action and resistance in breast cancer. Front Oncol. 2012; 2: 62
117. Arnould L, Gelly M, Penault-Llorca F, et al. Trastuzumab-based treatment of HER2-positive breast cancer: an antibody-dependent cellular cytotoxicity mechanism? Br J Cancer. 2006; 94: 259-267.

118. Vogel CL, Cobleigh MA, Tripathy D, et al. Efficacy and safety of trastuzumab as a single agent in first-line treatment of HER2-overexpressing metastatic breast cancer. Journal of Clinical Oncology. 2002; 20: 719-726.

119. Yang Y, Guo R, Tian X, et al. Synergistic anti-tumor activity of Nimotuzumab in combination with Trastuzumab in HER2-positive breast cancer. Biochemical and biophysical research communications. 2017; 489: 523-527.

120. Cameron D, Piccart-Gebhart MJ, Gelber RD, et al. 11 years' follow-up of trastuzumab after adjuvant chemotherapy in HER2-positive early breast cancer: final analysis of the HERceptin Adjuvant (HERA) trial. Lancet. 2017; 389: 1195-1205.

121. van Ramshorst MS, van Werkhoven E, Mandjes IAM, et al. Trastuzumab in combination with weekly paclitaxel and carboplatin as neo-adjuvant treatment for HER2-positive breast cancer: The TRAIN-study. Eur J Cancer. 2017; 74: 47-54

122. Marty M, Cognetti F, Maraninchi D, et al. Randomized phase II trial of the efficacy and safety of trastuzumab combined with docetaxel in patients with human epidermal growth factor receptor 2-positive metastatic breast cancer administered as first-line treatment: the M77001 study group. Journal of Clinical Oncology. 2005; 23: 4265-4274

123. Balduzzi S, Mantarro S, Guarneri V, et al. Trastuzumab-containing regimens for metastatic breast cancer. Cochrane Database Syst Rev. 2014; 12: CD006242.

124. Franklin MC, Carey KD, Vajdos FF, et al. Insights into ErbB signaling from the structure of the ErbB2-pertuzumab complex. Cancer Cell. 2004; 5: 317-328.

125. Loibl S, Jackisch C, Schneeweiss A, et al. Dual HER2-blockade with pertuzumab and trastuzumab in HER2-positive early breast cancer: a subanalysis of data from the randomized phase III GeparSepto trial. Ann Oncol. 2017; 28: 497-504.

126. von Minckwitz G, Procter M, de Azambuja E et al. Adjuvant Pertuzumab and Trastuzumab in Early HER2-Positive Breast Cancer. N Engl J Med. 2017; 377: $122-131$

127. Hu X, Huang W, and Fan M. Emerging therapies for breast cancer. Journal of hematology \& oncology. 2017; 10: 98.

128. Sabatier R, Finetti P, Mamessier E, et al. Prognostic and predictive value of PDL1 expression in breast cancer. Oncotarget. 2015; 6: 5449-5464.

129. Gibson J. Anti-PD-L1 for metastatic triple-negative breast cancer. Lancet Oncol. 2015; 16: e264.

130. Rojas K, and Stuckey A. Breast Cancer Epidemiology and Risk Factors. Clinical obstetrics and gynecology. 2016; 59: 651-672.

131. Lynch BM, Neilson HK, and Friedenreich CM. Physical activity and breast cancer prevention. Recent Results Cancer Res. 2011; 186: 13-42

132. Pisano ED, Hendrick RE, Yaffe MJ, et al. Diagnostic accuracy of digital versus film mammography: exploratory analysis of selected population subgroups in DMIST. Radiology. 2008; 246: 376-383.

133. Aysola K, Desai A, Welch C, et al. Triple Negative Breast Cancer - An Overview. Hereditary genetics : current research. 2013; 2013(Suppl 2): 001.

134. Wang J, Song C, Tang H, et al. miR-629-3p may serve as a novel biomarker and potential therapeutic target for lung metastases of triple-negative breast cancer. Breast Cancer Res. 2017; 19: 72

135. Mathe A, Scott RJ, and Avery-Kiejda KA. MiRNAs and Other Epigenetic Changes as Biomarkers in Triple Negative Breast Cancer. International journal of molecular sciences. 2015; 16: 28347-28376.

136. Massihnia D, Galvano A, Fanale D, et al. Triple negative breast cancer: shedding light onto the role of pi3k/akt/mtor pathway. Oncotarget. 2016; 7: 60712-60722.

137. Baselga J, Gomez P, Greil R, et al. Randomized phase II study of the anti-epidermal growth factor receptor monoclonal antibody cetuximab with cisplatin versus cisplatin alone in patients with metastatic triple-negative breast cancer. J Clin Oncol. 2013; 31: 2586-2592.

138. Anestis A, Karamouzis MV, Dalagiorgou G, et al. Is androgen receptor targeting an emerging treatment strategy for triple negative breast cancer? Cancer Treatment Reviews. 2015; 41: 547-553.

139. Gucalp A, Tolaney S, Isakoff SJ, et al. Phase II trial of bicalutamide in patients with androgen receptor-positive, estrogen receptor-negative metastatic Breast Cancer. Clin Cancer Res. 2013; 19: 5505-5512.

140. O'Shaughnessy J, Schwartzberg L, Danso MA, et al. Phase III study of iniparib plus gemcitabine and carboplatin versus gemcitabine and carboplatin in patients with metastatic triple-negative breast cancer. J Clin Oncol. 2014; 32: 3840-3847.

141. Basho RK, Gilcrease M, Murthy RK, et al. Targeting the PI3K/AKT/mTOR Pathway for the Treatment of Mesenchymal Triple-Negative Breast Cancer: Evidence From a Phase 1 Trial of mTOR Inhibition in Combination With Liposomal Doxorubicin and Bevacizumab. JAMA oncology. 2017; 3: 509-515.

142. Ropka ME, Keim J, and Philbrick JT. Patient decisions about breast cancer chemoprevention: a systematic review and meta-analysis. J Clin Oncol. 2010; 28: 3090-3095. 